\title{
Análisis del discurso irónico en el habla espontánea de las madres de Lima Norte a través de las distintas teorías pragmáticas
}

\author{
Ironic Speech Analysis in the Spontaneous Speech \\ of the Mothers of Lima North Through the Different \\ Pragmatic Theories
}

\author{
Sandra Desiree Estrada Cubas \\ Univ. Nacional Mayor de San Marcos \\ sandra.estrada1@unmsm.edu.pe
}

\author{
Mirella Alexandra Robles Muñoz \\ Univ. Nacional Mayor de San Marcos \\ mirella.robles@unmsm.edu.pe
}

\begin{abstract}
Resumen
El presente artículo revela el nivel de ironía en ciertas manifestaciones que poseen las madres de Lima Norte en su habla espontánea. Para ello se realizó un cuestionario con once preguntas, las cuales contienen información habitual en la comunicación entre madres e hijos; estas se agrupan de acuerdo a rasgos comunes y se aplica las teorías pragmáticas más plausibles para el análisis de los datos. Asimismo, se busca una generalización de los datos obtenidos, en base a las teorías aplicadas. Se concluye que los niveles de ironía que practican (consciente e inconscientemente) las madres son cambiantes y va a depender del tipo de pregunta que se les ha formulado, porque en algunos casos no hacen uso de este recurso. También, se consideran frases y figuras retóricas que acompañan al sentido figurado de los enunciados irónicos.
\end{abstract}

Palabras clave: Ironía, madres, Lima Norte, teorías pragmáticas, habla espontánea.

\begin{abstract}
This article reveals the level of irony in certain manifestations that the mothers of Lima North possess in their spontaneous speech. For this, a questionnaire was made with eleven questions, which contain common information in communication between mothers and offspring; these are grouped according to common features and the most plausible pragmatic theories are applied to the analysis of the data. Likewise, a generalization of the data obtained is sought, based on the theories applied. It is concluded that the levels of irony practiced (consciously and unconsciously) by mothers are changing and will depend on the type of question they have been asked, because in some cases they do not use this resource. Also, rhetorical phrases and figures that accompany the figurative sense of ironic statements are considered.
\end{abstract}

Keywords: Irony, mothers, Lima Norte, pragmatic theories, spontaneous speech. 
Sandra Desiree Estrada Cubas \& Mirella Alexandra Robles Muñoz

\section{Introducción}

Según Alvarado (2006), la ironía quizás constituye, junto con la metáfora y la representación del discurso, el fenómeno pragmático por excelencia. La ironía puede estar asociada a un efecto negativo, como la crítica o la burla, o a un efecto positivo, como la cortesía. En este trabajo se tomará la ironía como una afirmación doble, es decir, las frases dicen algo, pero transmiten otro mensaje, un mensaje implícito (la llamada 'implicatura conversacional' con matiz presuposicional) en el habla natural de las madres de Lima Norte. El significado irónico es siempre implícito. La ironía es una implicatura, que surge de la relación entre lo dicho o explícito y lo implicado, por lo general intencionalmente. Esta relación es producto de una manipulación del hablante.

En la Universidad Nacional Mayor de San Marcos se encuentran trabajos de presuposición pragmática e ironía verbal con Raymundo Casas Navarro, investigador especializado en tópicos relacionados con el lenguaje y la cognición. También se encuentran artículos valiosos en la Universidad de Alicante; y, en la universidad de Salamanca se halla una tesis doctoral de mucho valor con respecto a este tema, con autores como Grice o Ducrot, que realizan estudios a nivel profundo, donde tratan de establecer pautas o parámetros en el reconocimiento de un lenguaje irónico, todo ello en base a teorías pragmáticas aplicados en el lenguaje natural.

El objetivo del presente artículo es reconocer la ironía como un recurso habitual en el lenguaje de las madres al comunicarse con sus hijos; y, que, además, existen grados y factores que condicionan un enunciado como irónico o no. Este estudio es de vital relevancia porque muchas veces, en el habla habitual, se confunde un enunciado como irónico; y, en el fondo no lo es, debido a ello se presentan diferentes perspectivas, las cuales permiten dilucidar esta y otras interrogantes que se originan en la comunicación de índole irónica, analizadas desde el punto de vista del lenguaje irónico de las madres, pero cuyo estudio es capaz de ser aplicado en cualquier ámbito.

En la primera sección del artículo, se aprecia un resumen general de este; luego, tenemos una breve introducción donde se contextualiza y se percibe el objetivo general. En el siguiente apartado, se presenta aspectos teóricos, basados, principalmente, en teorías de carácter pragmático seleccionadas de tal forma que sean aplicadas directamente en el análisis del discurso irónico de las madres. Más adelante se muestra la metodología del artículo, la cual permite apreciar los medios y variables usadas para la obtención y recojo de datos. Por último, se

78 Lengua y Sociedad 
Análisis discurso irónico en el habla espontánea de las madres de Lima norte...

realiza un análisis riguroso considerando todas las teorías que contribuyan con el objetivo en mención.

\section{La ironía y sus teorías}

Hasta hace poco, la ironía se ha definido a partir de los parámetros de la retórica tradicional en los que se afirmaba que la ironía era decir lo contrario de lo que se quiere decir. En este sentido, la ironía, como figura literaria, usa recursos como la metáfora o la hipérbole para expresar un sentido negativo como contradicción o burla. Muecke (1978) nos menciona que los indicadores más comunes para reconocer la ironía son: la puntuación, las palabras de alerta, la colocación anómala de adverbios, las repeticiones, las yuxtaposiciones, el uso de evidenciales, la reinterpretación de unidades fraseológicas, la lítote, la hipérbole, la metáfora y el oxímoron; es decir, todos ellos pueden estar presentes al momento de analizar la ironía. Esta definición ha sido criticada por autores como Haverkate (1985), que considera que el concepto de contradicción no es suficiente para unificar todos los fenómenos irónicos. Además, la existencia de una contradicción no caracteriza a los enunciados como irónicos, ya que puede haber enunciados irónicos con sentido figurado que no llevan una contradicción implícita. En muchas ocasiones, lo que indica la ironía no es un significado opuesto, sino diferente.

Una de las primeras teorías que estudia la ironía es la teoría de los actos de habla, la cual sirve de núcleo a la primera teoría pragmática y es de especial importancia para todos los estudios dentro de esta disciplina, puesto que genera los conceptos pragmáticos que son imprescindibles para un análisis más amplio que el análisis semántico y sintáctico. De este modo, Austin (1962) introduce los niveles ilocutivo y perlocutivo para complementar el análisis que hasta la pragmática se basaba en el nivel locutivo. Sin embargo, esta no logra resolver muchos fenómenos comunicativos, sobre todo los actos indirectos, inclusivo la ironía.

Frente a ello, Grice propone la teoría de la conversación (1975), la cual estudia la ironía en el campo de la conversación, basado en la cooperación y producción. En esta teoría, el lenguaje irónico se relaciona con la violación de máximas durante la conversación y nos da la noción de reconocer enunciados irónicos.

Por otro lado, encontramos la teoría de la argumentación la cual postula la idea que el lenguaje irónico debe entenderse como el desacuerdo de los valores argumentativos entre el mensaje explícito y el implícito, Berrendonner (1981). 
Asimismo, postula la trasgresión de la regla argumental; es decir, el no postular dos valores distintos en un mismo enunciado, Anscombre y Ducrot (1983).

Estas teorías postulan, únicamente, el significado contradictorio de las expresiones irónicas. Posteriormente, se demostrará que las ironías guardan relación, también, con otros factores. Al interior de este campo, surge como planteamiento novedoso, la postura de Ducrot y su teoría polifónica que postula la yuxtaposición de voces en el lenguaje irónico. Esta última teoría presenta las bases para Sperber y Wilson.

Por ello, se estudia la ironía como fenómeno pragmático y se propone una teoría para el análisis que parte de las teorías neogriceanas, puesto que el hablante tiene una intención clara de comunicar algo cuando utiliza un enunciado irónico. De esta manera, pretende que su oyente infiera lo que no ha dicho para obtener el significado completo de su enunciación.

La Teoría de la Relevancia se ha pronunciado al respecto y ha propuesto una explicación para la ironía basada en el concepto de eco. Según Wilson y Sperber (2004: 265) «un enunciado es irónico porque es ecoico: la ironía verbal consiste en hacerse eco de un pensamiento o emisión que se atribuye de modo tácito, mediante una actitud distante y también tácita respecto a ella.» Por tanto, la ironía se estudia como un distanciamiento hacia un pensamiento o un enunciado atribuidos a alguien y siempre llevará consigo un contexto que pueda ser entendido como un eco burlón.

Según esta teoría toda ironía produce un eco con efecto negativo, es por ello que intentamos demostrar que no todo enunciado irónico lleva consigo ese eco burlón, sino que existe ironía con efecto positivo en la que la burla no está presente. Asimismo, estos mismos autores establecen pautas para detectar un lenguaje irónico, tales como que, el ironista simplemente debe interpretar lo que le parece es una implicación del comentario de su interlocutor. Si no existe un enunciado concreto, la fuente del eco es implícito, también se considera que el enunciado irónico logra su relevancia expresando la actitud hacia el pensamiento atribuido; $y$, que hay que decidir que el ironista se está disociando del pensamiento atribuido.

Entonces, Sperber y Wilson intentan resolver problemas del enfoque tradicional y rechazan la idea de ironía como significado figurado que indica lo contrario del significado literal, quitan relevancia al sentido figurado de las expresiones, consideran la primacía del sentido literal; ya que, primero se deben entender las expresiones tal y como son; es decir, el hablante debe ir ecoizando un enunciado

8o Lengua y Sociedad 
en su forma literal, consideran que la ironía no se reduce a la sustitución de un contenido explícito sobre otro implícito, como propuso Grice.

Sperber y Wilson postulan la idea de la actitud en las formulaciones originales de Grice, argumentan que el proceso de ecoización es el enunciado que conecta la actitud y viola la máxima de calidad, consideran importante un enunciado previo o un contexto relevante cuando el ironista está mencionando o un pensamiento atribuido para expresar su actitud disociativa hacia este.

Por otro lado, el grupo griale ha propuesto una explicación sistemática de la ironía que se apoya en la pragmática neogriceana. Sin negar el carácter particularizado de la ironía, consideramos imprescindible recurrir a aquellas inferencias generalizables que conllevan la codificación de algunos indicadores como irónicos. Así pues, la ironía supone la inversión del requisito previo de cualidad que ha de gobernar todo intercambio comunicativo. Dicha inversión repercute, de manera particularizada, en los principios conversacionales de Levinson (2000). Cuando la inversión irónica afecta al Principio de Cantidad («No proporcione una información más débil que el conocimiento del mundo que posee; en concreto, seleccione el elemento más fuerte del paradigma»), ciertos indicadores irónicos como los cuantificadores, los encomiásticos o los sufijos diminutivos se infieren de manera negativa. Cuando la inversión irónica afecta al Principio de Informatividad («Proporcione la información mínima que sea suficiente para conseguir sus propósitos comunicativos»), entran en juego las relaciones semánticas (polisemia, homonimia, antonimia). Cuando la inversión afecta al Principio de Manera («Indique una situación normal mediante expresiones no marcadas»), la variación (el cambio de registro, por ejemplo), el empleo de fraseología o de ciertas figuras retóricas (metáfora, hipérbole) activan las inferencias.

La ironía se concibe, por tanto, como fenómeno pragmático que se apoya en indicadores. El foco de atención lo constituye el enunciado lingüístico y su papel en la obtención de inferencias y, por extensión, en la progresión conversacional. En cambio, en las teorías que abordan el humor como interacción interesan, principalmente, los parámetros sociales (cortesía, relaciones de jerarquía, género, ámbitos laborales, familiares, etc.). 
Sandra Desiree Estrada Cubas \& Mirella Alexandra Robles Muñoz

\section{Metodología}

Para el análisis del discurso irónico de las madres de Lima Norte se realiza una encuesta con un total de 11 preguntas, las cuales contienen información de las formas usuales que poseen las madres al dialogar con sus hijos. Estas preguntas fueron seleccionadas con el fin de obtener frases y oraciones, teniendo estas un tono sarcástico, irónico y hasta persuasivo, por parte de las madres. La investigación es de carácter cualitativo porque se hace uso de una breve entrevista que no excedió, en muchos casos, los 10 minutos; cuyos datos arrojados (a manera de discursos) son analizados considerando la interpretación y contextualización de los informantes. Asimismo, se consideran los factores que intervienen, como la clase social y localidad a la que pertenecen las colaboradoras, rasgos importantes para apreciar la fluctuación irónica de las 18 madres encuestadas.

El recojo de datos se comienza a ejecutar el día 04 de mayo del presente año, culminando las entrevistas el día 26 de mayo de este. Las encuestas fueron realizadas, generalmente, en las tardes; debido a la disponibilidad de las madres. El demoro en la obtención de los datos se debe a la ubicación con respecto a las localidades de las madres, debido que se tenía que acudir hasta su propia localidad. Nuestra población comprende a las madres en general, porque son ellas las que nos permiten, a través de sus frases irónicas, realizar el objetivo del presente trabajo. La muestra corresponde a las madres que habitan en Lima Norte, específicamente en los siguientes distritos: Carabayllo, Comas, Los Olivos, Puente Piedra y San Martín de Porres. Se realizó una previa interacción con los informantes para que tengan confianza al responder las preguntas; asimismo, solo se utilizó una hoja y un lapicero para apuntar las respuestas.

\section{Análisis}

Para el análisis se realiza un proceso de selección, considerando contextos comunes que comparten las preguntas dirigidas a los informantes. Se consideran como evidencias, las respuestas más comunes, las más irónicas; y, las que no presentan este sentido irónico, con el fin de realizar un contraste. De igual forma, algunas preguntas presentarán respuestas donde solo prevalezca el sentido irónico.

82 Lengua y Sociedad 
Análisis discurso irónico en el habla espontánea de las madres de Lima norte...

\subsection{Contexto 1: El hijo llega de algún lugar en específico a casa.}

Respuestas a la pregunta 1 (Llega su hijo del colegio o centro de estudios y le pregunta qué hay de comer, ¿qué le respondería usualmente?)

(1) ¡Comida!

(2) Ante todo, primero es el saludo, luego puedes preguntarme qué hay de comer.

Respuestas a la pregunta 2 (Su hijo llega tarde de una reunión o fiesta y no le había avisado a la hora que llegaría, ¿qué le diría?)

(1) ¿Estas son horas de llegar?

(2) ¡Esto no es un hotel!

(3) ¡Otro día no te doy permiso por no respetar la confianza que te di!

\section{Reacción de las madres encuestadas}

Las primeras respuestas que se presentan como evidencias, tanto en la pregunta 1 como en la pregunta 2, son consideradas las más recurrentes, en las madres del Lima Norte, según la encuesta formulada. Se puede colegir, en base a estas primeras evidencias que las madres hacen uso, generalmente, de un lenguaje irónico cuando se presentan estos contextos. La ironía va acompañada, en estos casos, por un lenguaje con tono agresivo, juguetón y hasta cortante. El nivel de ironía se intensifica por la forma en cómo las madres expresan sus ideas; ya que, a veces contestan con la formulación de otras preguntas (como la evidencia 1 que responde a la pregunta 2); $y$, otras, al utilizar un lenguaje figurado (evidencia (2) ¡esto no es un hotel!), como recurso, para que se infiera de forma directa lo que en realidad las madres desean expresar que es su incomodidad por la tardanza del hijo. Algunas respuestas no son consideradas irónicas, como las respuestas (2) y (3) que corresponden a las preguntas 1 y 2, respectivamente, estas presentan un carácter netamente informativo y hasta consejero; no hay contradicción, eco burlón, ni sentido figurado al emitir, las madres, estos enunciados. 
Sandra Desiree Estrada Cubas \& Mirella Alexandra Robles Muñoz

\subsection{Contexto 2: El hijo es inconsciente de sus acciones}

Respuestas a la pregunta 3 (Su hijo le pide dinero de más para cosas que no le son necesarias, además de ello, están caras; considerando que usted anda con gastos y ajustando el dinero, ¿Qué le diría?)

(1) ¡No soy banco!

(2) No es necesario malgastar el dinero en algo por vanidad, hay que saber ahorrar porque nunca se sabe qué puede pasar después.

Respuestas a la pregunta 7 (Los amigos de su hijo vinieron temprano a su casa a jugar, a ver películas o cualquier cosa, menos a estudiar; y ya es demasiado tarde. ¿qué le diría a su hijo?)

(1) ¡Ya son las nueve y la visita no se mueve!

(2) ¿Hasta qué hora se van a quedar?

(3) No deberían jugar o hacer otras cosas mientras no han terminado las tareas.

Respuestas a la pregunta 9 (Le aconseja bastante a su hijo o hija sobre un tema en específico y por no hacerte caso le va mal, ¿Qué le diría?)

(1) ¿Ves?, ¡Te lo dije!

(2) Las personas mayores que tú ya han vivido lo que tú aún no vives, por eso damos buenos consejos y por lo tanto nos tienes que escuchar.

\section{Reacción de las madres encuestadas}

Se percibe que en todas las respuestas que corresponden a este contexto, por lo menos una presenta ironía; y, esta ironía, en los tres casos, va acompañado de un recurso retórico; por ejemplo, en la evidencia (1) que corresponde a la pregunta 3 (primer caso), la madre refiere la palabra 'banco' para enfatizar el sentido contradictorio de la función que realiza este sistema (transferir dinero). En la evidencia (1) que corresponde a la pregunta 7 (segundo caso), se percibe una especie de rima 'nueve' y 'mueve', para enfatizar, con un eco burlón, la incomodidad de la madre por la tardanza en la retirada de los amigos del hijo. La evidencia (1) que corresponde a la pregunta 9 (tercer caso), hace uso de los signos de interrogación 
Análisis discurso irónico en el habla espontánea de las madres de Lima norte...

y exclamación para enfatizar de manera burlesca el error del hijo. En la evidencia (2) que corresponde a la pregunta 7 , va a depender mucho de la manera en cómo se formule esta respuesta; ya que, presenta un sentido ambiguo entre ser irónico o no, dependerá de la intención del hablante. Existen respuestas en las cuales no se hayan atisbos de ironía, como, por ejemplo, en las últimas respuestas que se presentan en los tres casos.

\subsection{Contexto 3: El hijo presenta una posición rebelde frente a la madre}

Respuestas a la pregunta 4 (Ha cocinado una comida que no le gusta a su hijo (no lo hizo usted a propósito) y este no quiere comerla, ¿Qué le diría usualmente?)

(1) ¡Ya te lo comes o te lo metes por la nariz!

(2) Lo siento, es lo que hay

Respuestas a la pregunta 10 (Cuando le da órdenes a su hijo, ya sea de deberes o mandatos, y este no quiere obedecer, ¿Qué le dirías?)

(1) ¡No seas orejón!

(2) Comprende que muchas veces, si se te manda ciertos deberes es porque hay roles que debes cumplir, y a la vez hay que mostrar respeto a tus mayores.

\section{Reacción de las madres encuestadas}

Todas las respuestas que corresponden a la pregunta 4 presentan ironía, donde consideran como recursos el eco burlón y el sentido agresivo. También se percibe el sentido figurado, tanto en la evidencia (1) que corresponde a la pregunta 4, al utilizar la hipérbole como recurso que permite enfatizar el enojo de la madre cuando el hijo muestra rechazo hacia los alimentos que esta proviene; como en la evidencia (1) que corresponde a la pregunta 10, donde también hace uso de la hipérbole; pero, en este caso enfatiza la falta de obediencia que presenta el hijo. Estas hacen mostrar su carácter imponente y autoritario. En algunos casos hasta son desafiantes y chantajean a los hijos. En la pregunta 10, la evidencia (2) carece de sentido irónico, porque se muestra como un enunciado con carácter netamente consejero. 
Sandra Desiree Estrada Cubas \& Mirella Alexandra Robles Muñoz

\subsection{Contexto 4: El hijo muestra dependencia por parte de la madre}

Respuestas a la pregunta 5 (Su hijo le pregunta dónde están sus cosas cuando se supone que él debería saber, no usted, ¿Qué le respondería?)

(1) ¡En su sitio!

(2) En mi bolsillo.

(3) Tú debes saber dónde dejas tus cosas.

Respuestas a la pregunta 11 (Cuando su hijo quiere que le haga todas sus cosas como lavarle la ropa, cocinarle o arreglarle el cuarto; y usted ya está cansada de eso, ¿Qué le diría?)

(1) ¡Tienes tus manos!

(2) ¡Ya estás grande!, ya pasó la etapa de estar bajo el seno de tu madre, es tiempo de que vayas asumiendo tus responsabilidades.

\section{Reacción de las madres encuestadas}

Todas las evidencias que se presentan en el contexto 4 muestran un sentido irónico; sin embargo, se manifiestan de manera diferente. Las evidencias (1) y (2) que corresponden a la pregunta 5; y, la evidencia (1) que corresponde a la pregunta 11, muestran el sentido irónico acompañado de un eco burlón, llegando hasta un tono agresivo. Empero, en las evidencias (3) y (2) que corresponden a las preguntas 5 y 11, respectivamente, se manifiesta la ironía con efecto positivo; ya que, no está presente la burla, sino consejos con sentido acusativo que las madres manifiestan hacia sus hijos.

\subsection{Contexto 5: El hijo se muestra como irreverente}

Respuestas a la pregunta 6 (Su hijo quiere hacer algo que su amigo o amiga lo hizo, por ejemplo, un tatuaje, un piercing o un pintado de cabello y, obviamente, usted no quiere, ¿Qué le diría?)

(1) Si él come gusanos, ¿tú también vas a comer?

(2) ¡Qué bien por él! 
Análisis discurso irónico en el habla espontánea de las madres de Lima norte...

Respuestas a la pregunta 8 (Usted tiene un evento familiar muy importante, como un matrimonio, un bautizo o una fiesta; y su hija o hijo se vistió con ropa no adecuada, ¿Qué le diría?)

(1) ¿Acaso no tienes ropa?

(2) Hijita, por favor, cámbiate esa ropa no es la adecuada para la fiesta.

\section{Reacción de las madres encuestadas}

En el contexto 5, todas las evidencias presentan un lenguaje irónico; por ejemplo, en la evidencia (1) que corresponde a la pregunta 6, la madre hace uso del lenguaje figurado para chantajear de alguna manera a su hijo e influenciar en su decisión. En la evidencia (2) que corresponde, también, a la pregunta 6, la ironía se manifiesta del sentido contradictorio de lo que en realidad desea expresar la madre. En la pregunta 8 , la evidencia (1) refleja la ironía, como en el caso anterior, a través de la contradicción y el carácter burlesco. En la evidencia (2) que corresponde a la pregunta 8 , no presenta casos de ironía, pero sí se puede percibir el carácter persuasivo por medio de la súplica como recurso.

\section{Conclusiones}

Las madres de Lima Norte usan constantemente la ironía de forma consciente e inconsciente. Se concluye que los niveles de ironía de las madres son cambiantes; es decir, no muestran grados de ironía uniformes, ya que va a depender del tipo de pregunta que se les ha formulado y el contexto en el que se encuentren (algunas, como se presenta en la encuesta, muestran la ironía en sentido cortante, persuasivo, autoritario, etc.). También se perciben, en las respuestas, dos tipos de ironías (principalmente), la ironía con eco burlón (definición inherente al concepto de ironía), la cual se presenta como más recurrente en las encuestas; y, la ironía con sentido positivo, como se evidencia en nuestro corpus, son las que no presentan sentido burlesco, sino, más bien, una función consejera e informativa; pero sin perder el carácter persuasivo.

También observamos que en el lenguaje retórico encontramos el uso de la hipérbole en muchos de las respuestas que emiten las madres, como el uso del sentido contradictorio, el carácter burlesco y la manifestación del sentido figurado 
Sandra Desiree Estrada Cubas \& Mirella Alexandra Robles Muñoz

a través de frases que permiten la activación de las inferencias de forma directa. Asimismo, se usan signos de exclamación e interrogación, que ayudan a intensificar un enunciado irónico. Por último, se presentan, también, respuestas que carecen de sentido irónico y solo muestran una función netamente informativa.

\section{Bibliografía}

Alvarado, M. (2005). La ironía y la cortesía: una aproximación desde sus efectos. ELUA, 19, 33-45.

Alvarado, M. (2006). Las marcas de la ironía. Interlingüística, 16, 1-11.

Anscombre, J. y Ducrot, O. (1983). La argumentación en la lengua. Madrid: Gredos. Austin, J. (1962). How to Do Things with Words. Oxford: Oxford University Press. (traducción de Genaro R. Carrió y Eduardo A, Rabossi, Cómo hacer cosas con palabras, Barcelona: Paidós, 1998)

Berrendonner, A. (1981). Éléments de pragmatique linguistique. París: Éditions de Minuit. (traducción Elementos de pragmática lingüística, Barcelona: Gedisa, 1987).

Caro, M., Camargo, Z. y Uribe, G. (2018) La ironía re-visitada en sus dimensiones pragmáticas, comprensivas, discursivas y didácticas. Lenguaje, 46(1), 95-126.

Casas, J. (2017). Presuposición pragmática e ironía verbal: la cognición irónica (Tesis de maestría). Universidad Nacional Mayor de San Marcos, Lima.

Crespo, N., Benitez, R. y Caceres, P. (2007). La comprensión de las ironías orales. Estudios Filológicos, 42, 79-94.

Goubet, C. (2008). La ironía como recurso argumentativo-persuasivo en el discurso político de la prensa escrita. Cyber Humanitatis, 45. Recuperado de https://web.uchile.cl/vignette/cyberhumanitatis/cda/creacion_simple2/ 0,1241,scid\%253d21719\%2526isid\%253d738,oo.html

Haverkate, H. (1985). La ironía verbal: análisis pragmalingüístico. Revista Española de Lingüística, 15(2), 343-391. Recuperado de https://scielo.conicyt.cl/scielo. php?script=sci_arttext\&pid=So07117132007000100005

Kocman, A. (2011). La ironía verbal como semejanza incongruente (Tesis doctoral). Universidad de Salamanca, España.

Levinson, S. (2000). The Theory of Generalized Conversational Implicature. Cambridge: Massachusetts.

Muecke, D. (1978). Irony markers. Poetics (7), 363-375.

88 Lengua y Sociedad 
Análisis discurso irónico en el habla espontánea de las madres de Lima norte...

Reyes, G. (2004). Pragmática y metapragmática: la ironía lingüística. En I. Lerner, R. Nival, \& A. Alonso (Eds.), Actas del XIV Congreso de la Asociación Internacional de Hispanistas (Vol. 1, pp. 147-158). España: Centro Virtual Cervantes.

Ruiz, F. (2004). Principios cognitivos y pragmáticos del procesamiento y la comprensión. Arbor, 177(697), 128.

Ruiz, L. (2009). ¿Cómo se gestiona la ironía en la conversación?. Rilce, 25(2), 363-377.

Schmid, H.J. (2002). Cognitive Pragmatics. Berlin: De Gruyter Mounton.

Sperber, D. y Wilson, D. (2004). La teoría de la relevancia. Revista de Investigación Lingüística, (7), 237-286.

\section{Anexo 1}

Tabla 1: Ficha sociolingüística de las 18 madres encuestadas

\begin{tabular}{l|l|l|l|l|l}
\hline Hablante & Edad & \multicolumn{1}{|c|}{ Distrito } & \multicolumn{1}{|c|}{ NSE } & \multicolumn{1}{|c}{ Ocupación } & Edad del hijo \\
\hline H1 & 47 & Comas & Bajo & Ama de casa & 23 \\
\hline H2 & 41 & Carabayllo & Bajo & Cocinera & 21 \\
\hline H3 & 43 & S.M.P. & Medio - Bajo & Ambulante & 24 \\
\hline H4 & 36 & Carabayllo & Bajo & Ama de casa & 18 \\
\hline H5 & 48 & Comas & Bajo & Limpieza & 20 \\
\hline H6 & 54 & S.M.P. & Medio - Bajo & Vendedora & 22 \\
\hline H7 & 48 & Ventanilla & Bajo & Ama de casa & 23 \\
\hline H8 & 53 & Puente Piedra & Medio - Bajo & Contadora & 19 \\
\hline H9 & 45 & Comas & Medio & Docente & 26 y 15 \\
\hline H10 & 30 & Comas & Medio & Independiente & 10 \\
\hline H11 & 40 & Comas & Medio & Vendedora & 23 y 21 \\
\hline H12 & 45 & Comas & Medio & Ama de casa & 23 y 18 \\
\hline H13 & 55 & S.J.L. & Medio & Ama de casa & 32 \\
\hline H14 & 59 & Comas & Medio & Ama de casa & 40 \\
\hline H15 & 42 & Carabayllo & Medio & Administradora & 35 y 22 \\
\hline H16 & 54 & Comas & Medio & Vendedora & 12 \\
\hline H17 & 46 & Comas & Medio & Independiente & 23 y 27 \\
\hline H18 & 61 & Comas & Medio & Policía & 27,23 y 20 \\
\hline & & & & & \\
\hline
\end{tabular}




\section{Anexo 2}

Pregunta 1: Llega su hijo del colegio o centro de estudios y le pregunta qué hay de comer, ¿qué le respondería usualmente?

\begin{tabular}{l|l} 
Hablante & \multicolumn{1}{|c}{ Pregunta } \\
\hline H1 & ¡Qué te importa! ¡Tú solo come! \\
\hline H2 & ¡Tú solo come y calla! \\
\hline H3 & Cuando comas ya sabrás. \\
\hline H4 & ¡Qué niñito! \\
\hline H5 & ¡Comida! \\
\hline H6 & Cuando te sirva, sabrás. \\
\hline H7 & ¡Comida! \\
\hline H8 & Comidita de Dios. \\
\hline H9 & (Lo que ha cocinado la madre) ¡Eso es lo que hay! \\
\hline H10 & ¡Comida! \\
\hline H11 & (Lo que ha cocinado la madre). \\
\hline H13 & ¡Comida! ¡No preguntes! \\
\hline H14 & ¡Comida! Si no quieres, no comas. \\
\hline H15 & ¡Saluda primero y luego pregunta! \\
\hline H16 & (Nombre de la comida). \\
\hline H17 & Ante todo primero es el saludo, luego puedes preguntarme qué hay de comer. \\
\hline H18 & He cocinado bien rico, hijito. \\
\hline
\end{tabular}

Pregunta 2: Su hijo llega tarde de una reunión o fiesta y no le había avisado a la hora que llegaría, ¿qué le diría?

\begin{tabular}{l|l} 
Hablante & \multicolumn{1}{c}{ Pregunta } \\
\hline H1 & ¿Acaso no tienes casa? \\
\hline H2 & ¿Estas son horas de llegar?, señorita. \\
\hline H3 & ¿Hasta qué hora te di permiso? \\
\hline H4 & ¿Estas son horas de llegar?, jovencito. \\
\hline H5 & ¡Esto no es un hotel! \\
\hline H6 & ¿Acaso estas son horas de llegar? \\
\hline
\end{tabular}

\section{Lengua y Sociedad}


Análisis discurso irónico en el habla espontánea de las madres de Lima norte...

\begin{tabular}{l|l} 
Hablante & \multicolumn{1}{c}{ Pregunta } \\
\hline H8 & ¡Estas no son horas de llegar! \\
\hline H9 & ¿Hasta qué hora te di permiso? \\
\hline H10 & ¿Qué te dije? ¿Qué te dije? ¿Ves? \\
\hline H11 & ¿Por qué no avisaste que llegarías tarde? \\
\hline H12 & Ya no tienes casa, ¿no? \\
\hline H14 & $\begin{array}{l}\text { ¿Estas son horas de llegar? } \\
\text { ahora no lo entiendas, pero cuando estés en el papel de padre vas a saber cómo } \\
\text { se siente uno. }\end{array}$ \\
\hline H15 & ¡Otro día no te doy permiso por no respetar la confianza que te di! \\
\hline H16 & La próxima vez avisas para no preocuparme. \\
\hline H17 & $\begin{array}{l}\text { A la próxima, si vas a salir y consideras que llegarás tarde, avísame, por favor, } \\
\text { para no preocuparme. }\end{array}$ \\
\hline H18 & ¡Por qué no avisas carajo!, ¡estoy preocupada! \\
\hline
\end{tabular}

Pregunta 3: Su hijo le pide dinero de más para cosas que no le son necesarias, además de ello, están caras; considerando que usted anda con gastos y ajustando el dinero, ¿Qué le diría?

\begin{tabular}{l|l} 
Hablante & \\
\hline H1 & ¡Trabaja! \\
\hline H2 & ¿Acaso me crees banco? \\
\hline H3 & Nada de lujos \\
\hline H5 & ¡No fabrico dinero! \\
\hline H6 & ¿No soy banco! \\
\hline H7 & ¡No soy millonaria! \\
\hline H8 & ¡No tengo efectivo! \\
\hline H9 & ¡No hay plata! \\
\hline H10 & ¡No tengo!, ¡pídele a tu papá! \\
\hline H12 & No te voy a dar nada. \\
\hline T13 & ¿Seré tu banco acaso? \\
\hline H14 & $\begin{array}{l}\text { No es necesario malgastar el dinero en algo por vanidad, hay que saber ahorrar } \\
\text { porque nunca se sabe que puede pasar después. }\end{array}$ \\
\hline H15 & $\begin{array}{l}\text { Es mejor invertir en algo que realmente necesites y te sirva. En estos momentos } \\
\text { no te puedo dar lo que me pides. }\end{array}$ \\
\hline
\end{tabular}


Sandra Desiree Estrada Cubas \& Mirella Alexandra Robles Muñoz

\begin{tabular}{l|l} 
Hablante & \multicolumn{1}{|c}{ Pregunta } \\
\hline H16 & No te puedo dar porque ando con gastos, pero en cuanto tenga dinero te doy. \\
\hline H17 & $\begin{array}{l}\text { Comprende, en estos momentos no estamos en condiciones de hacer gastos } \\
\text { innecesarios, si fuera sumamente importante se haría lo posible por comprarlo. }\end{array}$ \\
\hline H18 & ¡No tengo!, yo cuando tengo te doy, y es mucho lo que me estás pidiendo. \\
\hline
\end{tabular}

Pregunta 4: Ha cocinado una comida que no le gusta a su hijo (no lo hizo usted a propósito) y este no quiere comerla, ¿Qué le diría usualmente?

\begin{tabular}{l|l}
\hline Hablante & \\
\hline H1 & ¡Come todo! O para la próxima no te guardo comida. \\
\hline H2 & ¡Come lo que hay! \\
\hline H3 & Algún día no tendrás qué comer. \\
\hline H5 & ¡Cuando tengas dinero comes lo que tú quieres! \\
\hline H6 & En la calle hay niños que no tienen ni qué comer y tú desperdiciando comida. \\
\hline H7 & ¡Piquito rico encima! \\
\hline H8 & ¡Es lo que hay, si no te gusta, cocina tú! \\
\hline H10 & Lo siento, es lo que hay. \\
\hline H11 & ¡Ya te lo comes o te lo metes por la nariz! \\
\hline H12 & Prepárate tu comida, entonces. \\
\hline H13 & Cocina tú, entonces. \\
\hline H14 & $\begin{array}{l}\text { El hambre no es cojudo, y tarde o temprano vendrás por esta olla a servirte tu } \\
\text { comida. }\end{array}$ \\
\hline H15 & ¡Cuando tengas hambre te lo comerás y tú misma te lo calentarás! \\
\hline H16 & Bueno, allí está tu comida, si no quieres comer ya es cosa tuya. \\
\hline H17 & $\begin{array}{l}\text { ¡Se tiene que comer lo que se cocina en casa!, así como hay comida que nos } \\
\text { gusta, también hay comida que no nos gusta. }\end{array}$ \\
\hline H18 & $\begin{array}{l}\text { ¡Te gusta las cosas ricas, pero también tienes que comer las cosas que no te } \\
\text { gustan pues! }\end{array}$ \\
\hline
\end{tabular}

Pregunta 5: Su hijo le pregunta dónde están sus cosas cuando se supone que él debería saber, no usted, ¿Qué le respondería?

\begin{tabular}{l|l}
\hline Hablante & \multicolumn{1}{c}{ Pregunta } \\
\hline H1 & ¡Yo qué sabré! \\
\hline H2 & ¿Acaso yo lo utilizo? \\
\hline
\end{tabular}


Análisis discurso irónico en el habla espontánea de las madres de Lima norte...

\begin{tabular}{l|l} 
Hablante & \\
\hline H3 & ¡Dónde lo habrás dejado! \\
\hline H4 & ¡En su sitio! \\
\hline H5 & ¡Tú sabrás! \\
\hline H6 & ¡Se habrá ido al vecino seguro! \\
\hline H7 & ¡Tú debes saber! \\
\hline H8 & Ni idea. \\
\hline H9 & En mi bolsillo. \\
\hline H10 & No sé, serán mis cosas seguro. De repente tienen patas y se fueron caminando. \\
\hline H11 & Donde siempre está. \\
\hline H12 & Por eso debes organizarte. \\
\hline H13 & Tú sabrás pues, si son tus cosas. \\
\hline H14 & $\begin{array}{l}\text { ¡Debes tener más orden con tus propias cosas, ya estás grande y no eres un niño } \\
\text { como para estar repitiéndote cómo hacer bien las cosas! }\end{array}$ \\
\hline H15 & Estará donde lo dejaste, hijita. \\
\hline H16 & Tú debes saber dónde dejas tus cosas. \\
\hline H17 & ¡Ten más orden al colocar tus cosas, ya que son tuyas! \\
\hline H18 & ¡Ahorita voy y las encuentro y qué te hago! \\
\hline
\end{tabular}

Pregunta 6: Su hijo quiere hacer algo que su amigo o amiga lo hizo, por ejemplo, un tatuaje, un piercing o un pintado de cabello y, obviamente, usted no quiere, ¿Qué le diría?

\begin{tabular}{l|l} 
Hablante & \multicolumn{1}{c}{ Pregunta } \\
\hline H1 & ¡Te haces algo y te olvidas que soy tu madre! \\
\hline H2 & Si él come gusanos, ¿tú también vas a comer? \\
\hline H3 & ¡Tu problema! \\
\hline H4 & Si tu amigo se mata, ¿tú también te matas? \\
\hline H6 & Si tu amigo se tira del cerro, ¿tú también lo harás? \\
\hline H7 & ¡Ten personalidad, no vas a estar haciendo lo que otros hacen! \\
\hline H8 & ¡Qué bien por él! \\
\hline H9 & ¡Ah! O sea, porque tu amigo se tira del puente, tú también lo vas hacer. \\
\hline H10 & ¡No y simplemente no! \\
\hline H12 & ¡Si el amigo se mata, también te matas tú! \\
\hline H13 & Ven acá que yo te lo hago. \\
\hline
\end{tabular}




\section{Sandra Desiree Estrada Cubas \& Mirella Alexandra Robles Muñoz}

\begin{tabular}{|c|c|}
\hline Hablante & Pregunta \\
\hline H14 & $\begin{array}{l}\text { ¡No hagas las cosas por monería!, recuerda que esa decisión puede tener una } \\
\text { consecuencia. }\end{array}$ \\
\hline H15 & $\begin{array}{l}\text { Cuando tengas una edad adecuada, serás consciente de las decisiones que tomes } \\
\text { y ya sabrás qué hacer. }\end{array}$ \\
\hline H16 & No tienes que hacer todo lo que tus amigos hacen. \\
\hline H17 & $\begin{array}{l}\text { Piensa bien si realmente deseas hacértelo, y si quieres hacértelo, háztelo, pero no } \\
\text { por intentar copiar a los demás. }\end{array}$ \\
\hline H18 & ¡Tú te haces y vas a ver lo que yo te hago! \\
\hline
\end{tabular}

Pregunta 7: Los amigos de su hijo vinieron temprano a su casa a jugar, a ver películas o cualquier cosa, menos a estudiar; y ya es demasiado tarde. ¿qué le diría a su hijo?

\begin{tabular}{|c|c|}
\hline Hablante & Pregunta \\
\hline $\mathrm{H} 1$ & ¡Ya es hora! \\
\hline $\mathrm{H} 2$ & ¿Acaso no tienen sus propias casas? \\
\hline H3 & ¡Ya, no quiero bulla por favor! \\
\hline $\mathrm{H} 4$ & ¡Arrancando, arrancando! \\
\hline $\mathrm{H} 5$ & ¡Ya son las nueve y la visita no se mueve! \\
\hline H6 & ¿Sus padres no se preocupan por ellos? \\
\hline $\mathrm{H} 7$ & ¿Qué, se van a quedar a dormir? \\
\hline $\mathrm{H} 8$ & ¡Ya es hora! \\
\hline H9 & ¿Hasta qué hora se van a quedar? \\
\hline H10 & ¿Ya acabaron?, ¿ya terminaron? \\
\hline H11 & ¡Que ya se retiren a su casa!, sus papás deben estar preocupados. \\
\hline H12 & No pierdas el tiempo. \\
\hline H13 & ¿Ya? \\
\hline H14 & ¡Primero son tus deberes, después puedes relajarte! \\
\hline H15 & $\begin{array}{l}\text { ¡Ya es hora que tus amigos regresen a casa porque ya jugaron, vieron peli, etc... } \\
\text { entonces ya toca que se retiren. }\end{array}$ \\
\hline H16 & No deberían jugar o hacer otras cosas mientras no han terminado las tareas. \\
\hline H17 & $\begin{array}{l}\text { ¡Primero debes cumplir con tus obligaciones, con tus responsabilidades!, ya } \\
\text { luego puedes jugar. }\end{array}$ \\
\hline H18 & $\begin{array}{l}\text { ¡Rápido arreglas ese problema y manda a todos a dormir, a su casa; y tú también } \\
\text { descansa, antes que delante de ellos te haga pasar vergüenza!. }\end{array}$ \\
\hline
\end{tabular}

\section{Lengua y Sociedad}


Análisis discurso irónico en el habla espontánea de las madres de Lima norte...

Pregunta 8: Usted tiene un evento familiar muy importante, como un matrimonio, un bautizo o una fiesta; y su hija o hijo se vistió con ropa no adecuada, ¿Qué le diría?

\begin{tabular}{l|l} 
Hablante & \\
\hline H1 & ¡Así no me vas! \\
\hline H2 & ¿Acaso no tienes ropa? \\
\hline H3 & ¡Arréglate un poco, mi hijo! \\
\hline H4 & ¡Qué fachas son esas! \\
\hline H5 & ¡Pareces loca vestida así! \\
\hline H6 & ¿Qué, así vas a ir? \\
\hline H8 & ¡Pareces un pordiosero! \\
\hline H9 & ¡Al menos péinate! \\
\hline H10 & ¡Te cambira!, ¡no estás para la ocasión! \\
\hline H11 & ¡Cámbiate de ropa, eso no es para que vayas al evento! \\
\hline H12 & Me vas a hacer pasar vergüenza, ¡cámbiate! \\
\hline H13 & ¡Qué es eso! \\
\hline H14 & ¡Cámbiate!, para este tipo de eventos uno tiene que estar formal \\
\hline H15 & Hijita, por favor, cámbiate esa ropa no es la adecuada para la fiesta. \\
\hline H16 & ¡Ponte una ropa más apropiada para la situación! \\
\hline H17 & $\begin{array}{l}\text { ¡Cámbiate!, elige una ropa adecuada; ya que para momentos importantes hay } \\
\text { que vestirse de acuerdo a la ocasión. }\end{array}$ \\
\hline H18 & ¡Me voy sola, no me voy contigo hasta que te vistas como gente! \\
\hline
\end{tabular}

Pregunta 9: Le aconseja bastante a su hijo o hija sobre un tema en específico y por no hacerte caso le va mal, ¿Qué le diría?

\begin{tabular}{l|l} 
Hablante & \\
\hline H1 & ¡Bien hecho por desobediente! \\
\hline H2 & ¡Lo sabía! \\
\hline H3 & Tienes que aprender a escuchar a tu madre. \\
\hline H4 & ¡Bien hecho, por orejón! \\
\hline H5 & ¿Ves?, ¡Te lo dije! \\
\hline H6 & ¡Te dije! \\
\hline H8 & ¡Sabía que pasaría! \\
\hline H9 & ¡Sabía que eso sucedería! \\
\hline H10 & ¿Qué te dije?, ¿ves?, ¿qué te dije?, por no escuchar. \\
\hline
\end{tabular}


Sandra Desiree Estrada Cubas \& Mirella Alexandra Robles Muñoz

\begin{tabular}{l|l} 
Hablante & \multicolumn{1}{c}{ Pregunta } \\
\hline H11 & ¡Ves!, ¡te lo dije!, por qué no haces caso a la mamá. \\
\hline H12 & Te lo dije, piensas que estoy loca, pero verás. \\
\hline H13 & Ya ves, yo te dije. \\
\hline H14 & $\begin{array}{l}\text { Las madres sabemos cuándo uno puede correr un riesgo, ya que tenemos más } \\
\text { experiencia en esta vida. Todo consejo de una madre siempre es para bien. }\end{array}$ \\
\hline H15 & $\begin{array}{l}\text { Las personas mayores que tú ya han vivido lo que tú aún no vives, por eso damos } \\
\text { buenos consejos y por lo tanto nos tienes que escuchar. }\end{array}$ \\
\hline H16 & $\begin{array}{l}\text { No lo digo a cada rato para no molestarte, pero está bien que te pase para que } \\
\text { aprendas y tomes conciencia. }\end{array}$ \\
\hline H17 & $\begin{array}{l}\text { ¡Escúchame!, toma en cuenta mis consejos porque soy tu madre y siempre voy a } \\
\text { desear lo mejor para ti. }\end{array}$ \\
\hline H18 & ¡Por qué no atiende y no hace caso a lo que su madre le dice! \\
\hline
\end{tabular}

Pregunta 10: Cuando le da órdenes a su hijo, ya sea de deberes o mandatos, y este no quiere obedecer, ¿Qué le dirías?

\begin{tabular}{l|l} 
Hablante & \\
\hline H1 & ¡Acá se hace lo que yo digo! \\
\hline H2 & ¿No haces caso, no? ¡Ya hablé! \\
\hline H3 & ¡Haz caso pues! \\
\hline H4 & ¡No seas orejón! \\
\hline H5 & ¡Mientras vivas bajo mi techo, harás lo que te digo! \\
\hline H6 & ¡Obedece! \\
\hline H7 & ¡Hazme caso, soy tu madre! \\
\hline H8 & ¡No seas malcriado! \\
\hline H10 & ¿Hasta qué hora te voy a esperar? \\
\hline H11 & ¡Ponte hacer lo que te estoy diciendo! \\
\hline H12 & Crees que yo hablo por las puras. \\
\hline H13 & ¿Hasta qué hora? \\
\hline H14 & ¡Tarde o temprano vas a necesitar algo de mí! \\
\hline H15 & ¡Lo tienes que hacer sí o sí!, en casa todos tenemos responsabilidades. \\
\hline H16 & ¡Si no lo haces, no me pidas favores! \\
\hline H17 & $\begin{array}{l}\text { Comprende que muchas veces, si se te manda ciertos deberes es porque hay roles } \\
\text { que debes cumplir, y a la vez hay que mostrar respeto a tus mayores. }\end{array}$ \\
\hline H18 & ¡Mira, yo me voy a parar aquí, delante de ti, hasta que no hagas lo que te he dicho! \\
\hline
\end{tabular}


Análisis discurso irónico en el habla espontánea de las madres de Lima norte...

Pregunta 11: Cuando su hijo quiere que le haga todas sus cosas como lavarle la ropa, cocinarle o arreglarle el cuarto; y usted ya está cansada de eso, ¿Qué le diría?

\begin{tabular}{|c|c|}
\hline Hablante & Pregunta \\
\hline $\mathrm{H} 1$ & ¡Tienes tus propias manos!, hijito. \\
\hline $\mathrm{H} 2$ & ¡Te pasas! (después lo termina haciendo) \\
\hline $\mathrm{H} 3$ & ¡Ya estás grandecito! \\
\hline $\mathrm{H} 4$ & ¡Acá no tienes empleadas! \\
\hline H5 & ¡Tienes tus manos! \\
\hline H6 & ¡No, no, mi hijito! \\
\hline $\mathrm{H} 7$ & ¡No soy tu sirvienta! \\
\hline $\mathrm{H} 8$ & ¡Cada uno con sus cosas! \\
\hline H9 & Sabes qué, ¡háztelo tú! \\
\hline H10 & ¡Qué!, ¿yo soy tu empleada? \\
\hline H11 & ¿Soy tu mamá o tu sirvienta? \\
\hline H12 & ¿No tienes manos o qué? \\
\hline H13 & ¡Hazlo tú! \\
\hline H14 & $\begin{array}{l}\text { ¡Ya estás grande!, ya pasó la etapa de estar bajo el seno de tu madre, es tiempo de } \\
\text { que vayas asumiendo tus responsabilidades. }\end{array}$ \\
\hline H15 & ¡Soy tu madre, no tu empleada! \\
\hline H16 & $\begin{array}{l}\text { ¡Tú también eres capaz de hacerlo, no todo el tiempo voy a estar para ti!, } \\
\text { ¡deberías aprender! }\end{array}$ \\
\hline $\mathrm{H} 17$ & $\begin{array}{l}\text { Aprende a cooperar en la casa, que también como mamá necesito que me ayudes, } \\
\text { la labor del hogar no es solo de la mamá sino de todos quienes viven en ella. }\end{array}$ \\
\hline H18 & $\begin{array}{l}\text { ¡Qué te has creído, oye!, ¿crees que yo soy tu sirvienta?, ¡tienes tus manos y eres } \\
\text { lo suficientemente fuerte para hacerlo!, ¡no me jodas! }\end{array}$ \\
\hline
\end{tabular}

